American Journal of Agricultural and Biological Sciences 7 (2): 143-149, 2012

ISSN 1557-4989

(C) 2012 Science Publications

\title{
Simulation of Soybean Growth under Sowing Date Management by CROPGRO Model
}

\author{
${ }^{1}$ Farzad Paknejad, ${ }^{2}$ Pouria Farahani Pad, \\ ${ }^{1}$ Mohammad Nabi Ilkaee and ${ }^{3}$ Faezeh Fazeli \\ ${ }^{1}$ Department of Agronomy and Agriculture Research Center, \\ Karaj Branch, Islamic Azad University, Karaj, Iran \\ ${ }^{2}$ Young Researcher Club Roudehen Branch, \\ Islamic Azad University, Roudehen, Iran \\ ${ }^{3}$ Department of Environment, Faculty of Civil Engineering, \\ Shahid Rajaee Teacher Training University, Tehran, Iran
}

\begin{abstract}
Problem statement: Always because of weather change, determine of optimum sowing date in each zone is difficult. Dynamic models can help us for solving this problem. In order to evaluation of soybean simulation by using of CROPGRO-Soybean model at four sowing date in field research of Azad university of Karaj branch a field experiment conducted in form of split plot in based on randomize complete block design with four replication in 2009s. Approach: At this experiment simulation of some traits such Leaf Area Index (LAI), Leaf Dry Weight (LDW), Stem Dry Weight (SDW) and Biomass (B) evaluated for cv. Williams using of CROPGRO-Soybean. According to results, model was successful in the traits simulation, because of high Wilmot coefficient produced (0.6), 20 days after planting to the end of the growth duration. Results: Model explained well stem dry weight, as correlation coefficient in each sowing date was significant $(\mathrm{p}<0.01)$. Simulation precision for biomass was suitable, as coefficient differentiation was significant $(\mathrm{p}<0.01)$ for first to fourth sowing date (S1-S4) 0.889, 0.986, 0.909 and 0.796, respectively. These statistic parameters designated high ability of model for simulation of some traits measured in soybean for four sowing date management. Conclusion: We can use by model for sowing date management of soybean in Karaj climate condition, of course after repetitions of experiment and doing of model calibration. We proposed that soil and weather data measured in each place of experience and also plant morphology parameter measured precisely because this help to us for obtaining of objects.
\end{abstract}

Key words: CROPGRO-Soybean, simulation, LAI, leaf, stem and total dry weight, soybean, sowing date

\section{INTRODUCTION}

Obtaining of suitable model dynamic for planning sowing date management under each climate condition is important why that in basis it we can predict of many traits such biomass, grain yield, harvest index in different sowing date managements. Also using suitable model we can in basis sensitivity analysis obtained the most important factors affect on growth and development (Nasiri mahalati, 1999). Using crop model for agronomy management on physiological traits in crops caused that we reached to object, earlier (Boote $e t$ $a l ., 2001)$. In analysis and resolution of growth indexes, were affected different factors such as sowing date and environmental condition. Sowing date by ways of changes of days length, photosynthesis rate and respiration affected on growth properties and dry matter production. Determining of suitable planting time cause to early, fast, uniformity and full germination, that this factor redound to soil cover faster, more sun radiation interception and light penetration reduction into canopy and increased crop competition capability opposite weeds (Latifi et al. 2004). According to (Hundale and Kaur, 1997) reports, using CERES- Wheat model for predicting grain yield in Panjab climate condition, also in irrigation management (Lobell and Ortiz-Manasterio, 2006) was successfully. Also (Landau et al., 1998) after simulation of wheat growth using CERES- Wheat pay to model test and validation it's.

With attention to access identified and management methods of limited growth indexes factor, need to achievement of permanent and expensive

Corresponding Author: Farzad Paknejad, Department of Agronomy and Agriculture Research Center, Karaj, Branch, Islamic Azad University, Karaj, Iran Tel: +98 (261) 3202523/+98 9126723289 
experiments in different of years and locations, therefore find out methods for reduce of expensive mention is necessary (Goudriaan, 1977). To days achievement of this important by simulation of growth vegetative and reproductive processes using computer software predicated on mathematics equation and with acted to high effective variables on yield have been possible (Wolfram, 1991). Simulation models for improve making of crop production management are used noticeably (Nasiri mahalati, 1999; Bouman et al., 1996). In developing country because of much expensive consumed for entrance of oil and protein products, therefore efficiency improvement of oil and protein grain in this country is very important. With attention to CROPGRO-Soybean model ability in determination of quantity effect of different climatic and environmental parameters on Soybean production, can with selection different strategic such as production evaluation of different varieties, sowing date, investigation of nitrogen consumption rate and time and also effects this factors by weather data in long time, we can evaluated growth, development and yield in Soybean in zonal and international levels (Bhatia et al., 2008). According to (Vrishali et al., 2004) CROPGRO model validation under grain and pod yield predicting, was about $17 \%$. In this model, error percent for LAI and stem weight (to rate $38 \%$ ) was highest rate. Altogether presented model predicted well (with error 12\%) harvest index. Stockle (2007) simulated some traits such: LAI, total dry matter, physiological maturity for Soybean using of CROPSYST model in based on weather and soil data. Comparison of simulation and observed results in field shown that model simulated successfully grain yield, total dry matter and LAI. This experiment conducted with aim to CROPGRO model evaluation for simulation of growth, development and yield in four Soybean cv. and four sowing date in Karaj zone.

\section{MATERIALS AND METHODS}

In order to evaluation of CROPGRO-Soybean model on Soybean (cv. Williams) under four different planting date in Karaj weather condition an experiment carry out in form of split plot in based on randomize complete block design with four replicate in research field Islamic Azad university of Karaj branch in 2010 $\left(35^{\circ} 43^{\prime} \mathrm{N}, 50^{\circ} 49^{\prime} \mathrm{E}\right.$, altitude 1174 Meter sea level (MSL). Experimental factors was four different planting date 19 May (S1), 29 May (S2), 9 Jun (S3), 19 Jun (S4) as main plot and Soybean cv. Williams as sub plot. Each plot designed six rows of $6 \mathrm{~m}$ length and inter and intra spacing of $0.5 \mathrm{~m}$ and 8 centimeters, respectively with plant density $25 \mathrm{plant} / \mathrm{m}^{2}$. Primary plow and disc applications were conducted to depth 30 $\mathrm{cm}$ and $15 \mathrm{~cm}$, respectively and then land surfacing carry out by leveler. Nitrogen manure with scale 150 $\mathrm{kg} / \mathrm{ha}$ according to soil test to equal ratio at three stage before planting, flowering time and pod stage added to each plot. Seed soybean after disinfection and planted at four sowing date to soil depth $3 \mathrm{~cm}$, by hand and then plant density regulated to rate of $25 \mathrm{plant} / \mathrm{m}^{2}$. Primary irrigation conducted after sowing and second irrigation 4 days next and others weekly. Weed control carry out in several turns by hand. At first we required information for simulation including soil, weather and plant data supplied and identified to CROPGROSoybean. Then measured traits data identified to model in specific sites. At the end was a compared simulated and measured trait.

Management data: Field management data including, plot dimensions, planting inter and intra, sowing depth, plant density, supplying land implementation, experimental treatments, cultivar identification and its genetic coefficient, irrigation management, sowing date, harvest time and soil important physical and chemical properties.

Soil data: Soil data including of physical and chemical properties at three different layers include surface, average and deep of soil such as: color, texture, density, organic percent, nitrogen, phosphorous and potassium available, soil pH, electrical conductance soil (EC).

Experimental data: Experimental data including of measured traits during growth processes (at 8 stages) and measured traits at the end of maturity.

Weather data: Weather data including of the most important parameters affected on growth include minimum and maximum daily temperature (Celsius), daily rain $(\mathrm{mm})$ and sunny hours. The 20 days after planting to 10 days interval in 8 states was took samples at $1 \mathrm{~m}$ plant line to considering of edge effects for measuring some traits such leaf area, leaf and stem, biomass weight.

Model evaluation: Analysis of data and means comparison achieved using SAS program with Duncan method, respectively. For comparison of simulated data among measured data were used evaluation indexes such, Willmot agreements index (d) (Wilmot, 1982) and $\mathrm{R}^{2}$ coefficient in line regression curve $(1: 1)$ (Eitzinger et al., 2004). If d coefficient rate obtained by model was near to 1 showing that model successful at simulation of that trait. According to many reports of modelers, in basis of sample number, $d$ coefficient upper than 0.65 showed that model simulation is acceptable. If $\mathrm{R}^{2}$ rate in line $1: 1$ near to 1 , in fact, model description will suitable for its trait. In evaluation of model ability for trait predicting, $r$ (correlation coefficient) rate in basis sample number for 8 sample 0.66-0.79 $(\mathrm{p}<0.05)$ and $\mathrm{r}>0.79 \quad(\mathrm{p}<0.01)$ will significant (Soltani et al., 2005; Ehdaee, 2002). 
Am. J. Agri. \& Biol. Sci., 7 (2): 143-149, 2012

\section{RESULTS}

LAI simulation: According to Table 1, Wilmot coefficient (Wilmot, 1982) for LAI in cv. Williams in all of sowing dates obtained more than 0.60 , this was proof why model power was suitable for trait simulation. The highest and lowest of model precise rate equal to 0.93 and 0.754 for sowing dates of third and first, respectively (Fig 1). The result showed that variation coefficient $R^{2}$ 0.675-0.936 obtaining of linear regression analysis in functions simulated among predicted for LAI, showing that model described well trait variation process (Table 1).

Table 1: Comparison of simulated and measured rates of LAI (line 1:1)

\begin{tabular}{llll}
\hline $\mathrm{D}$ & $\mathrm{R}^{2}$ & $\mathrm{Y}=\mathrm{X}$ & Sowing date \\
\hline 0.754 & $0.675^{* *}$ & $\mathrm{Y}=0.603 \mathrm{X}$ & First \\
0.889 & $0.936^{* *}$ & $\mathrm{Y}=0.683 \mathrm{X}$ & Second \\
0.93 & $0.704^{* *}$ & $\mathrm{Y}=1.074 \mathrm{X}$ & Third \\
0.889 & $0.534^{*}$ & $\mathrm{Y}=1.159 \mathrm{X}$ & Fourth \\
\hline
\end{tabular}

Ns, ${ }^{*}, *$ No significant, significant at level $\% 0.05$ and 0.01 , respectively
Table 2: Comparison of simulated and measured rates of leaf dry weight (line 1:1)

\begin{tabular}{llll}
\hline $\mathrm{D}$ & $\mathrm{R}^{2}$ & $\mathrm{Y}=\mathrm{X}$ & Sowing date \\
\hline 0.608 & $0.356 \mathrm{~ns}$ & $\mathrm{Y}=1.322 \mathrm{X}$ & First \\
0.679 & $0.716^{* *}$ & $\mathrm{Y}=1.960 \mathrm{X}$ & Second \\
0.65 & $0.934^{* *}$ & $\mathrm{Y}=2.786 \mathrm{X}$ & Third \\
0.666 & $0.978^{* *}$ & $\mathrm{Y}=2.742 \mathrm{X}$ & Fourth
\end{tabular}

Ns, ${ }^{*}, * *$ No significant, significant at level $\% 0.05$ and 0.01 , respectively

Table 3: Comparison of simulated and measured rates of stem dry weight (line 1:1)

\begin{tabular}{llll}
\hline $\mathrm{D}$ & $\mathrm{R}^{2}$ & $\mathrm{Y}=\mathrm{X}$ & Sowing date \\
\hline 0.868 & $0.628^{* *}$ & $\mathrm{Y}=0.937 \mathrm{X}$ & First \\
0.934 & $0.906^{* *}$ & $\mathrm{Y}=1.285 \mathrm{X}$ & Second \\
0.797 & $0.929^{* *}$ & $\mathrm{Y}=1.920 \mathrm{X}$ & Third \\
0.762 & $0.853^{* *}$ & $\mathrm{Y}=10976 \mathrm{X}$ & Fourth \\
\hline
\end{tabular}

Ns, ${ }^{*}, * *$ No significant, significant at level $\% 0.05$ and 0.01 , respectively

Table 4:Comparison of simulated and measured rates of biomass (line

\begin{tabular}{llll}
\multicolumn{2}{c}{$1: 1)$} & & \\
\hline $\mathrm{D}$ & $\mathrm{R}^{2}$ & $\mathrm{Y}=\mathrm{X}$ & Sowing date \\
\hline 0.947 & $0.889^{* *}$ & $\mathrm{Y}=0.804 \mathrm{X}$ & First \\
0.985 & $0.986^{* *}$ & $\mathrm{Y}=1.156 \mathrm{X}$ & Second \\
0.899 & $0.909^{* *}$ & $\mathrm{Y}=1.479 \mathrm{X}$ & Third \\
0.876 & $0.796^{* *}$ & $\mathrm{Y}=1.428 \mathrm{X}$ & Fourth \\
\hline
\end{tabular}

Ns, ${ }^{*}, * *$ No significant, significant at level $\% 0.05$ and 0.01 , respectively
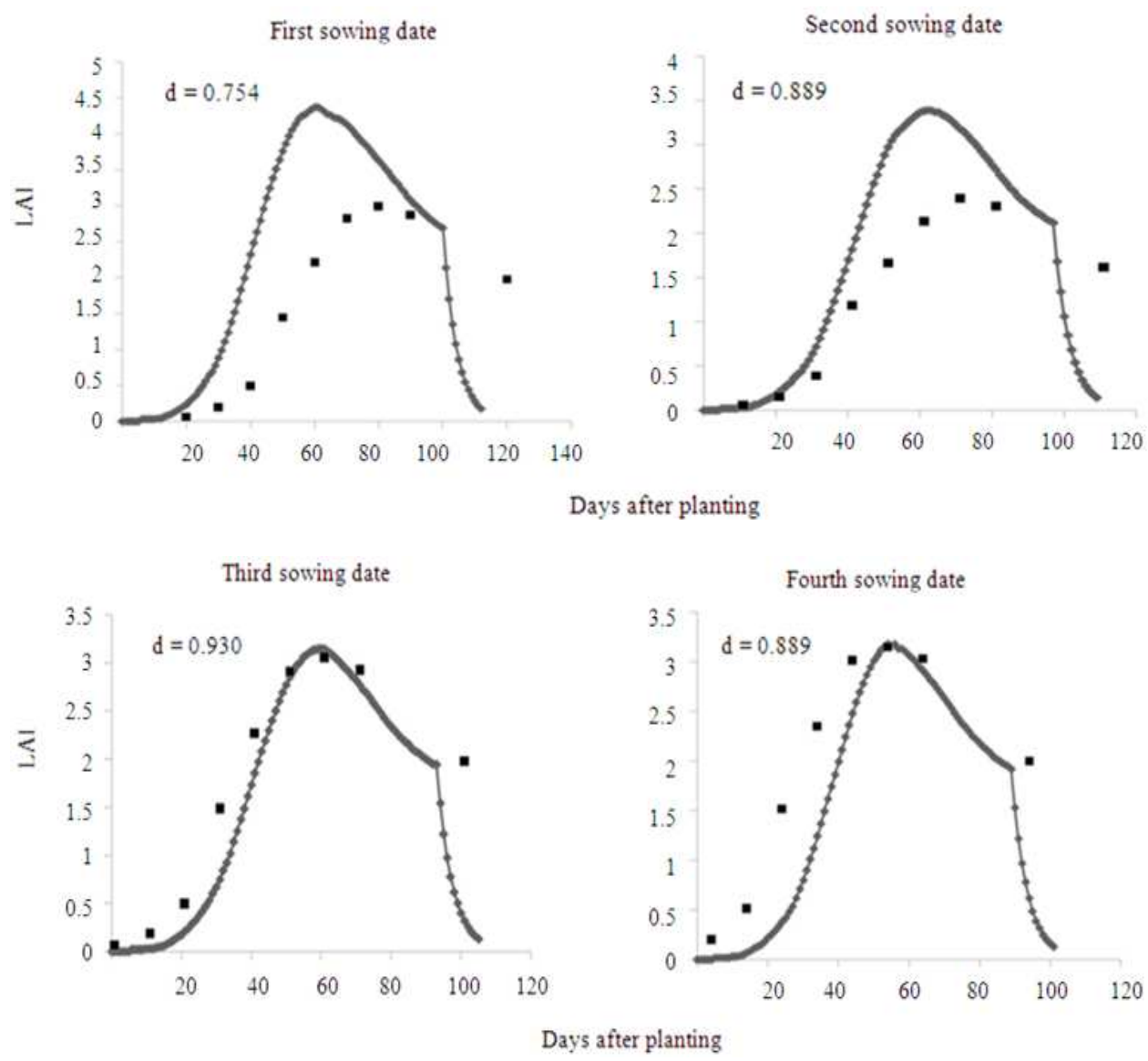

Fig. 1: Simulated (line) and measured (square) rates of LAI under four sowing date 
Am. J. Agri. \& Biol. Sci., 7 (2): 143-149, 2012
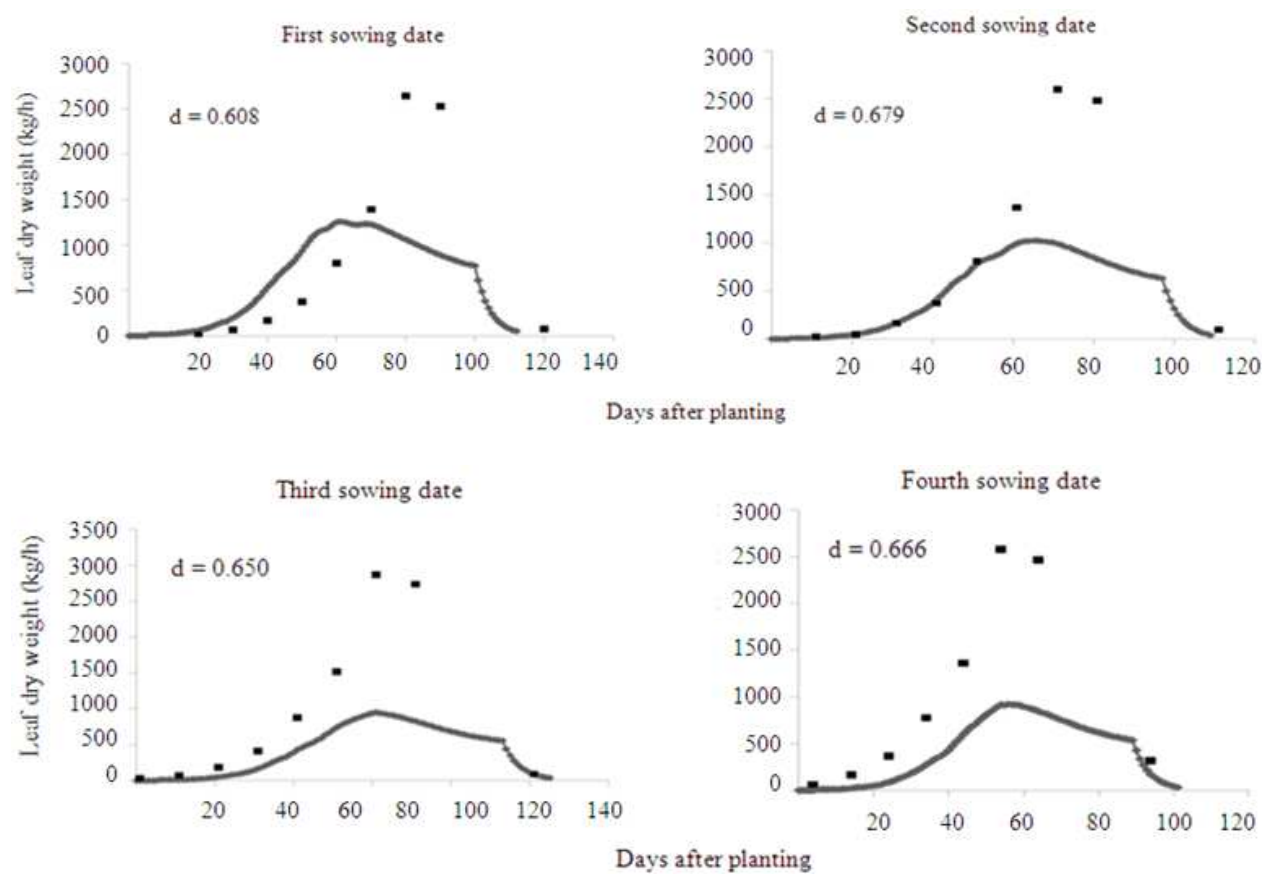

Fig. 2: Simulated (line) and measured (square) rates of leaf dry weight under four sowing date
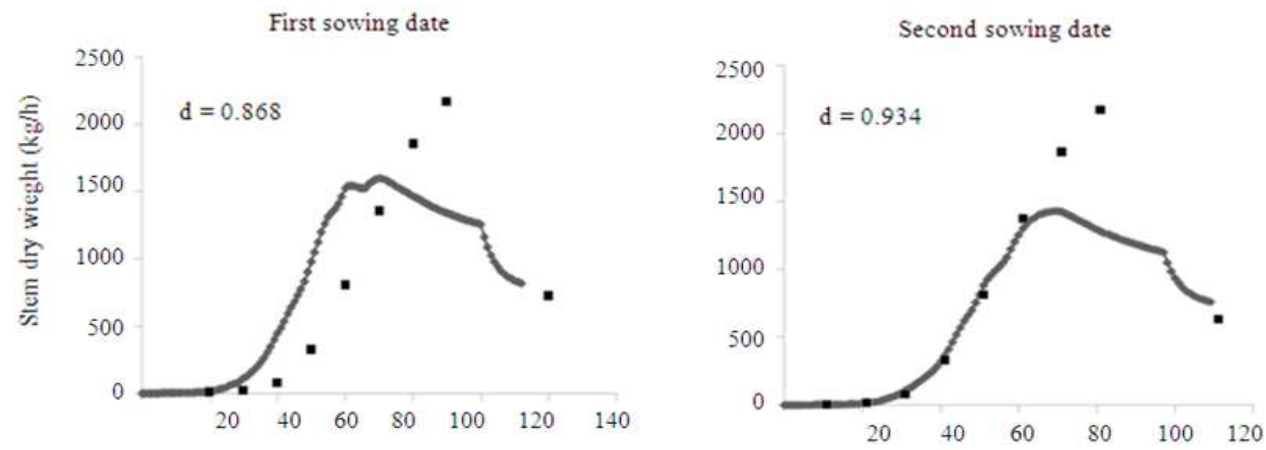

Days after planting
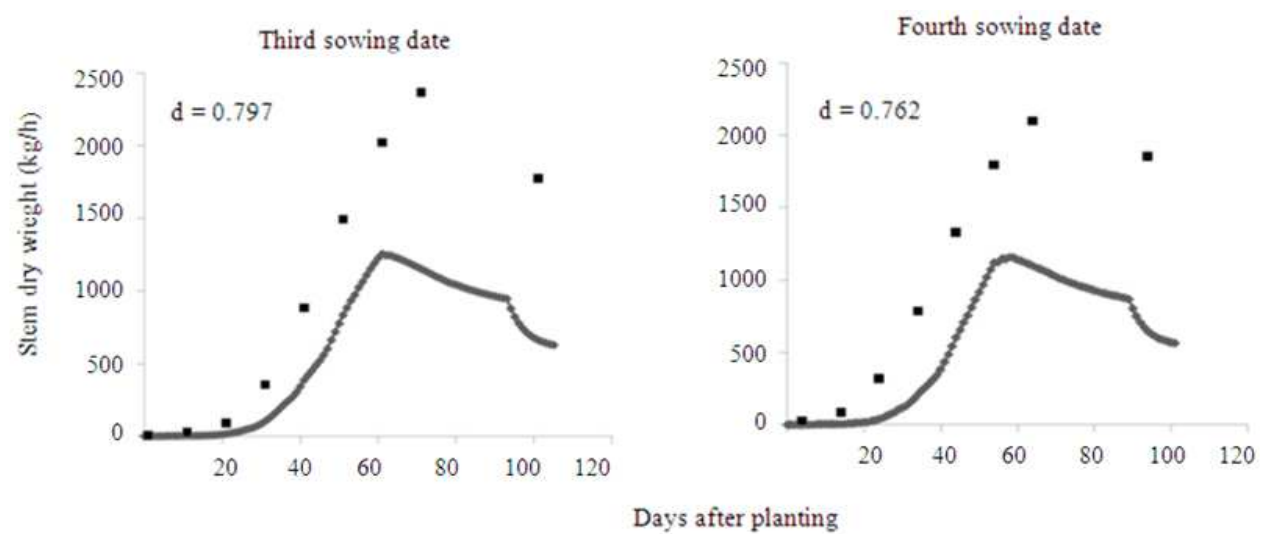

Fig. 3: Simulated (line) and measured (square) rates of stem dry weight under four sowing date 146 
Am. J. Agri. \& Biol. Sci., 7 (2): 143-149, 2012
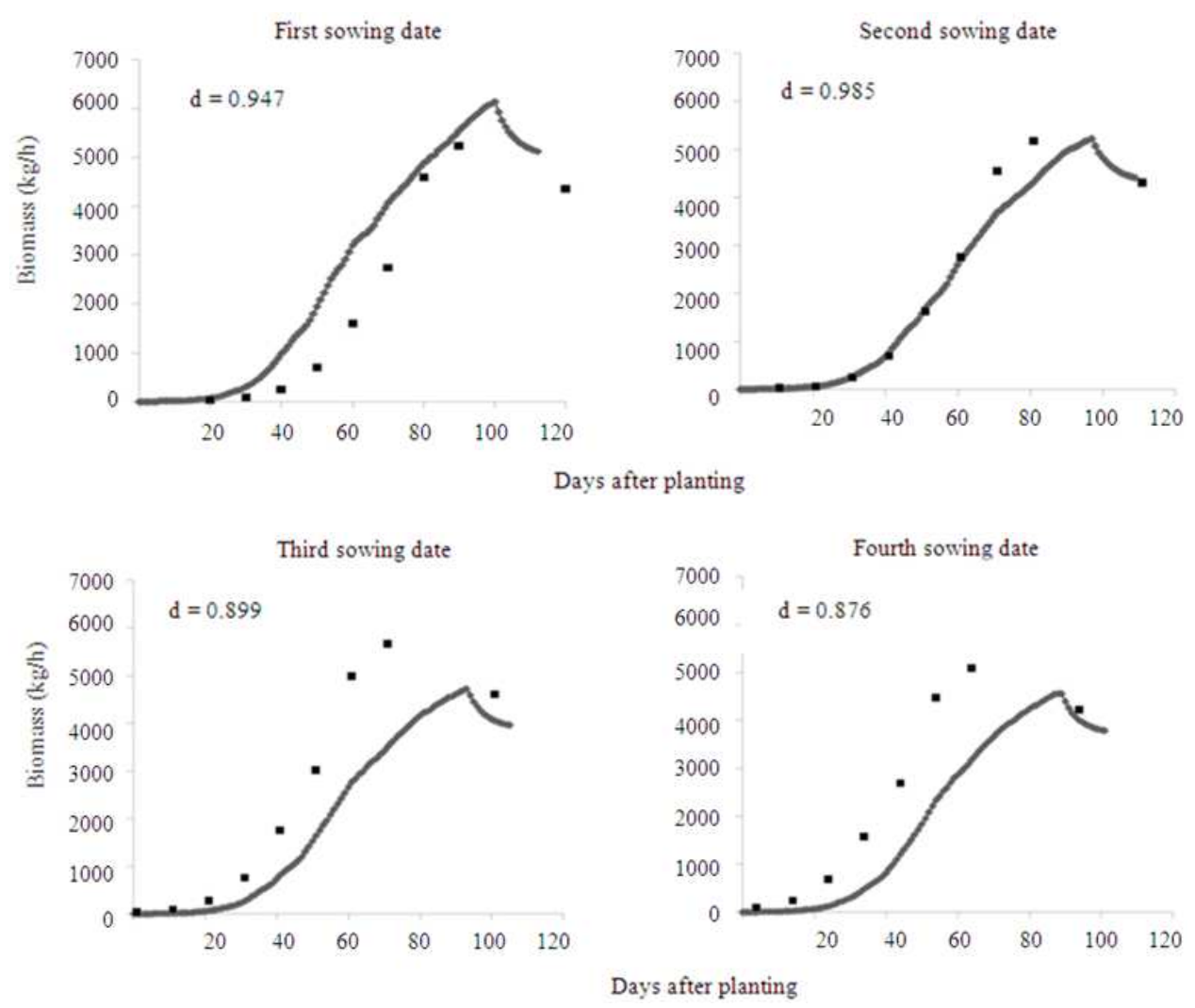

Fig. 4: Simulated (line) and measured (square) rates of biomass under four sowing date

Leaf weight simulation: $R^{2}$ coefficient obtained of line (1:1) for leaf dry weight in different sowing dates showing that model simulation has been suitable ability (Table 2). Variation dimension of $\mathrm{R}^{2}$ coefficient between 0.356-0.978, showed that model in some treatments was not acted well and in some of treatments acted excellent (Table 2). Variation dimension of $\mathrm{d}$ coefficient was between 0.608-0.679, showed that model could be predicted acceptably variation trait under four sowing date. According to Fig. 2, model predicted approximately suitable variation process of leaf dry weight in all of treatments, but at two sampling stages 80 and 90 days after planting, simulated rates was so much less than measured data.

Stem dry weight simulation: According to results of regression curve (line 1:1) for stem dry weight in all of sowing date, model had been suitable description for this trait (Table 3). Variation dimension rate $\mathrm{R}^{2}$ for all of treatments was differed 0.628-0.929 and correlation coefficient in all of treatments at levels $\mathrm{p}<0.01$ was significant (Ehdaee, 2002). Variation process simulated and measured rates for stem dry weight in all of sowing dates by model had been $\mathrm{d}$ coefficient $0.762-0.934$ showing that model predicted well variation process of this trait (Fig. 3).

Biomass simulation: $\mathrm{R}^{2}$ coefficient in line $(1: 1)$ between measured and simulated biomass near to 1 and showing that model had successful for predicting of biomass in different sowing date (Table 4). Variation dimension of $\mathrm{R}^{2}$ varied $0.796-0.986$, this result show that model could be predicted suitably biomass in four sowing date (Table 1). According to Fig. 4 biomass process for simulated and measured data in all of the sowing date, show that variation dimension of $d$ coefficient had been $0.876-0.985$, as model simulated well biomass in different sowing dates (Fig. 2). Model predicted biomass in third and fourth sowing date lower than measured field data (Fig. 4).

\section{DISCUSSION}

According to Fig. 1 at first sowing date because of colder weather, with decreasing respiration, LAI improvement was more than other sowing dates and model predicted well this occurrence. Reduction of model precision in first sowing date, probably to reason 
of unsuitable plant standing under field condition, therefore for obtaining of better results we must be applied all of the management details. Model CROPGRO-Soybean in study of LAI predicting was used continually. By using of this model (Shrikant and Jones, 2002) presented acceptable predicting for LAI in Soybean under different climate condition. Existing of weeds in each of growth stage and unsuitable separation of plant constitutive details such leaf, stem and pod affected on measured error increasing (Soltani et al., 2005). In many studies about simulation of the leaf dry weight, further account to more error in comparison to biomass and for determine of gap yield, biomass production in canopy is more important than leaf weigh (Bhatia et al., 2008).

Reduction of model predicting precise in sowing date third and fourth, probably because account to unsuitable weather and go away from growth potential caused reduction of predicting precise (Hundale and Kaur, 1997). Reason of lower estimation biomass in third and fourth sowing dates, probably became because of emergence unsuitable condition in basis of account to warm weather and creation of uniformity in plant standing (Mahallati, 2000). Suitable predicting of Soybean biomass in different sowing date showed that this traits in this model could be predicted well dry matter production in basis of uptake of sun radiation by plants green cover, maximum and minimum temperature, in potential growth condition. According to Harnos (2006), CROPGRO-Soybean model could be predicted well biomass in 9 different zones, variation dimension of $\mathrm{R}^{2}$ obtained to 0.98-0.95.

\section{CONCLUSION}

Results of evaluation of CROPGRO-Soybean in this study showed that, generally model in different sowing date management simulated total biomass better than grain yield, stem and leaf dry matter. Model in simulation of total dry matter in four sowing date acted well. If this process continued in several years in same zone, we can used model after calibration its due to grain yield, stem and leaf dry matter for research objects and management programming, specially about determination of optimum sowing date.

\section{REFERENCES}

Bhatia, V.S., P., Singh, S.P., Wani, G.S., Chauhan and A.V.R, Rao, et al., 2008. Analysis of potential yields and yield gaps of rainfed soybean in India using CROPGRO-Soybean model. Agric. Forest. Meteorol., 148: 1252-1265. DOI: 10.1016/j.agrformet.2008.03.004
Boote, K.J., M.J., Kropff and P.S. Bindraban, 2001. Physiology and modelling of traits in crop plants: Implications for genetic improvement. Agric. Syst., 70: $\quad 395-420 . \quad$ DOI: $\quad 10.1016 / \mathrm{S} 0308-$ $521 \mathrm{X}(01) 00053-1$

Bouman, B.A.M., H. Van Keulen, H.H. Van Laar and R. Rabbinge, 1996. The 'School of de Wit' crop growth simulation models: A pedigree and historical overview. Agric. Syst., 52: 171-198. DOI: 10.1016/0308-521X(96)00011-X,

Ehdaee, B., 2002. Common experimental statistic. Publisher Mashhad Barsava.

Eitzinger, J., M. Trnka, J. Hosch and Z. Zalud, M. Dubrovsky, 2004. Comparison of CERES, WOFOST and SWAP models in simulating soil water content during growing season under different soil conditions. Ecol. Model., 171: 223246. DOI: 10.1016/j.ecolmodel.2003.08.012

Goudriaan, J., 1977. Crop Micrometeorology: A Simulation Study. 1st Edn., Centre for Agricultural Publishing and Documentation, Wageningen, ISBN-10: 902200614X. pp: 249.

Harnos, N., 2006. Applicability of the AFRCWHEAT2 wheat growth simulation model in Hungary. Applied Ecol. Environ. Res., 4: 55-61.

Hundale, S.S and P. Kaur, 1997. Application of the CERES-Wheat model to yield predictions in the irrigated plains of the Indian Punjab. J. Agric. Sci. Camb., 129: 13-18.

Landau, S., R.A.C. Mitchell, V. Barnett and J.J. Colls, J. Craigon et al., 1998. Testing winter wheat simulation models' predictions against observed UK grain yields. Agric. Forest Meteorol., 89: 8599. DOI: 10.1016/S0168-1923(97)00069-5

Latifi, N., A. Soltani and D. Spanner, 2004. Effect of temperature on germination components in Canola cultivars. Iranian, J. Agric. Sci., 35: 313-321.

Lobell, D.B. and I. Ortiz-Manasterio, 2006. Evaluating strategies for improved water use in spring wheat with CERES. Agric. Water Manage., 84: 249-258. DOI: 10.1016/j.agwat.2006.02.007

Mahallati, M.N., 2000. Modeling of growth process in crops. University Jehad of Mashhad.

Shrikant, S.J. and J.W. Jones, 2002. Adaptation and evaluation of the CROPGRO-soybean model to predict regional yield and production. Agric. Ecosyst. Environ., 93: 73-85. DOI: 10.1016/S01678809(01)00358-9

Soltani, A., M. Gholipoor and A. Haji-Zadeh, 2005. SBEET: A simple model for simulation sugar beet yield. J. Agric. Sci. Technol. Mashhad, 19: 11-25. 
Stockle, C.O., 2007. The cropSyst model: A brief description. Biological systems engineering dep., Washington state University, Pullman, Wa, USA.

Vrishali D., C. Salunke and A. Akmanchi, 2004. Estimation of Soybean growth and yield by CROPGRO-Soybean model. Technolngy Report 2.04, Indian Council of Agriculture Research, University of Pune, New Dehli.
Wilmot, C.J., 1982. Some comments on the evaluation of model performance. Bull. Am. Meteorol. Soc., 63: 1309-1313. DOI: $10.1175 / 1520-$ 0477(1982)063<1309:SCOTEO >2.0.CO;2

Wolfram, S., 1991. Mathematica: A System for Doing Mathematics by Computer. 2nd Edn., AddisonWesley Publishing Company, Redwood City, Calif., USA., ISBN-10: 0201515024, pp: 961. 